\title{
Dental educators' views and knowledge of competencies required within a competency framework
}

SADJ September 2021, Vol. 76 No. 8 p482 - p489

RD Maart', RZ Adam², JM Frantz ${ }^{3}$

\begin{abstract}
Aims

The aim of the study was twofold; first was to explore and describe dental educators' views of the competencies required within the AfriMEDS core competency framework. The second was to highlight the views of the dental educators, regarding the alignment of the AfriMEDS core competencies, with the dental curriculum.
\end{abstract}

\section{Methods}

A case study approach to qualitative inquiry was used. The participants were purposefully selected, and two focus group discussions were conducted. An interview protocol was used to guide the discussions. The gathered data from the discussions were transcribed verbatim, and uploaded to the Atlas ti program for data analysis. Themes were identified from the findings of the thematic analysis.

\section{Results}

Dental educators required some guidance and clarity on the AfriMEDS core competency framework. However, they were able to recognize the competencies related to the AfriMEDS core competency framework. Two of these competencies, evidence-based dentistry, and private practice, were highlighted as core competencies in this current study; however, in AfriMEDS, only certain aspects of this was described.

\section{Conclusion}

The results of this current study revealed that dental educators were able to make valuable recommendations about the additional competencies requirements for dental graduates.

\section{Author affiliations:}

1. Ronel D. Maart: $B C h D, M P h i l, P h D$ (candidate), HOD Prosthetics, Faculty of Dentistry, University of the Western Cape. https://orcid. org/0000-0002-1560-040X

2. Razia, Z. Adam: $B C h D, M S c, P h D$, Senior lecturer, Restorative Dentistry, Faculty of Dentistry, University of the Western Cape, https://orcid.org/0000-0002-2645-9878

3. José M. Frantz: PhD, DVC: Research and Innovation, Department of Physiotherapy, University of the Western Cape. https://orcid.org/0000-0002-8296-5601

Corresponding author: Ronel D. Maart

Private Bag XI, Tygerberg, 7505. South Africa. Email: rmaart@uwc.ac.za. Cell: +27219373181 . South Africa

The role played and the respective contribution:

Ronel D Maart: Principle author 50\%

Razia Z Adam : Co-author 25\%

Jose M Frantz : Co-author 25\%
Keywords

Competency based education, Research Methodology Qualitative, Faculty Dental, Dental educators, competencies, competency framework, qualitative research.

\section{INTRODUCTION}

Dental education in the twenty-first century is guided by societal and delivery changes, improvements in oral health, advances in science and technology, together with the complexity of the current evolving environment. ${ }^{1}$ In addition to these changes, over the last decade, dental education has transitioned from traditional to competency-based education (CBE), with competencies requirements for dental graduates on graduation. In the past, educational practice has been to teach students increments of prescribed subject matter, the traditional curriculum, whereas the essence of CBE is that the success of dental, or allied health curricula should be judged in terms of its impact on students, expressed as competency outcomes. ${ }^{2}$

Competency is a complex behavior, or ability that is essential to initiate independent and unsupervised practice of a professional role, such as dentistry. ${ }^{3}$ It comprises an intertwined array of numerous components, namely, capacity to apply knowledge, experience, critical thinking capability, problem solving skills, ethical values, and the capacity to perform tasks in accordance with established criteria. ${ }^{3}$ Globally, competencies for dental graduates have been described in literature. .,5, $6^{-1}$ The American Dental Education Association (ADEA) approved the following competencies for the new general dentist: 1) critical thinking, 2) professionalism, 3) communication and interpersonal skills, 4) health promotion, 5) practice management and informatics, 6) patient care. A (assessment, diagnosis and treatment planning) and patient care B (establishment and maintenance of oral health). ${ }^{5}$ Similarly, the majority of Canadian dental programs adopted a national consensus document, specifying competencies for a beginning dental practitioner in $1994 .^{6}$ This document comprises 47 competency statements. Canadian dental programs have used these competencies to guide the curriculum content, as well as provide evidence of curriculum outcomes. ${ }^{6}$

To ensure the provision of high-quality oral healthcare, it is essential to equip dentists with the competencies to cope with the challenges of every day dental practice. The University of Texas Health Sciences Center at San Antonio, involved their faculty, students, alumni, and outside consultants to re-evaluate the competencies 
of their program, to ensure they were contemporary, and the methods used to assess them, were valid and reliable. ${ }^{7}$ As dental educators have the responsibility of synchronizing the undergraduate dental education with the clinical reality, ${ }^{8}$ the assumption is that they would be ideally suited to provide input regarding dental graduates' competencies. Gaps in dental education have been identified from the perspectives of students, alumni, faculty members, employers, and patients. ${ }^{7}$

Various core competency frameworks inform dental curricula for dental schools, globally, and in South Africa, the African Medical Education Directions for Specialists (AfriMEDS) guides the dental curricula for all the dental schools in the country. The AfriMEDS framework also guides the accreditation process of all medical and dental schools in South Africa. ${ }^{9}$ AfriMEDS was adapted from the Canadian Medical Educational Directives for Specialists (CanMEDS). ${ }^{9}$ The reason for this adoption, and supplementary modification, was to align the framework in the South African and the wider African context, and to be sufficiently generic, to guide the training of all health professionals. AfriMEDS core competencies framework is related to the following seven roles: Health Professional, Communicator, Collaborator, Health Advocate, Professional, Scholar and Leader and Manager. ${ }^{10}$

The Global Oral Health Interest Group of the Consortium of Universities for Global Health initiated recommendations for core competencies in the education of health care professionals, and specific groups of the public, relevant to oral health. ${ }^{11}$ This process recognized the lack of consensus on global oral health competencies, as a major disparity in the education of health professionals. Improvement needs that were identified by stakeholders, namely, students and faculty, are of particular value, as they are based on personal and direct experiences of successful, or unsuccessful outcomes, which could be used as a road map for curricular changes. ${ }^{12}$

As stakeholders, dental educators in South African dental schools are expected to map the dental graduates' competencies throughout the undergraduate dental curricula, for the accreditation process. In addition to this, the scope of the dental educators, includes teaching, assessment, and clinical supervision of undergraduate dental students, as well as contributing to this accreditation process, with the guidance of, inter alia, deans and committees. Additionally, changes associated with practicing dentistry in the $21 \mathrm{st}$ century, which explore competencies required for dental graduates, specific to the unique context of the graduates' practice, seems appropriate. Many studies on perceptions, including evaluations, of dental education have focused on student views, especially regarding curriculum content, delivery (teaching) and learning. ${ }^{12}$ However, the views of dental educators, regarding the competencies of dental graduates, are equally important. In addition, published literature, on the core competencies required upon graduation of dental graduates in South Africa, is non-existent. Therefore, in this current study, the researchers aimed to explore and describe the dental educators' views of competencies required, in the AfriMEDS core competency framework. In addition, the aim was to highlight the views of the dental educators, regarding the alignment of the AfriMEDS core competencies, with the institutions' undergraduate dental curriculum.

\section{MATERIAL AND METHODS}

A case study approach to qualitative inquiry was used in this study. ${ }^{13}$ This allowed the researchers to explore the dental educators' views of the core competencies required, in the AfriMEDS framework for dental graduates. The population for this current study was dental educators from one of the universities in South Africa. The participants were purposefully selected, and included dental educators, who were module coordinators of clinical modules. This sampling was an attempt to provide cases, relevant to the research question, which were rich in information, and would provide in-depth insight. ${ }^{14}$ Dental educators are responsible for teaching, learning, as well as clinical teaching of undergraduate dental students. The population comprised, approximately, 60 dental educators, of whom 14 (2 groups of 7 ) were purposively selected to represent the 7 clinical disciplines at this institution, using the following criteria: They had to be full-time dental educators, with a dentistry degree; and they had to be module coordinators of clinical disciplines (Clinical Dentistry, Conservative dentistry, Prosthetics, Maxillo- facial surgery, Paediatric dentistry, Orthodontics, Oral Medicine and Periodontology), from the second, third, fourth and final year of the respective courses.

The university Dentistry Calendar 2019 was used to access all the clinical modules offered in the undergraduate curriculum, and invitation emails were sent to these module coordinators. Two dates were set, and the selected participants' engagement were scheduled for dates that best suit them. Focus group discussions, as the data collection method of choice, were conducted in English with two groups of seven full-time dental educators. A semi-structured interview guide was used for the focus group discussions and, with permission from the participants, the focus group discussions were audio-recorded.

The primary researcher conducted the focus group discussions. Each participant was assigned a number from one to seven, and were instructed to refer to this number, when they responded during the discussion. At the start of the discussions, the primary researcher was introduced, as well as the research assistant, and the participants, before the focus group discussion-process/ procedure was outlined. Both focus group discussions were recorded by means of a voice recorder, while the research assistant recorded field notes. An independent transcriber was used to transcribe the data of both focus group discussions. The transcriptions of both focus group discussions were uploaded on the Atlas ti computer program for data analysis. After the transcriptions were read and re-read, codes were assigned, based on the literature, and the use of descriptive words, or phrases. This data analysis was an iterative process. Subsequently, code groups were generated by categorizing similar codes that displayed interrelationships. ${ }^{13}$

Ethics clearance to conduct this current study was obtained from the Biomedical Research Ethics Committee at the University (BM 19/1/23). Before each focus group discussion, information sheets, outlining the aim of the study, were emailed to all the participants. In addition, consent forms were emailed to the participants, while confidentiality was 
Table 1: Competency themes, categories and quotes from focus group participants.

\begin{tabular}{|c|c|c|}
\hline Major Competency theme & Categories & Quotes from participants \\
\hline \multirow[t]{2}{*}{ 1. Defining clinical competence } & $\begin{array}{l}\text { 1.1. Clinical competence includes assessment, } \\
\text { diagnosis and treatment plan }\end{array}$ & $\begin{array}{l}\text { "Able to gather clinical data and to use that data to render a diag- } \\
\text { nosis and from that diagnosis to be able to develop a treatment } \\
\text { plan and so that is a competency that we strive for and when we } \\
\text { say develop a treatment plan." 1FG5 }\end{array}$ \\
\hline & $\begin{array}{l}\text { 1.2. Clinical competence requires a holistic and } \\
\text { collaborative approach }\end{array}$ & $\begin{array}{l}\text { "That we try or we tell our students that you must look at it holis- } \\
\text { tically and not just look at the tooth that we treating in the clinic or } \\
\text { the denture you making." 1FG7 }\end{array}$ \\
\hline 2. 'Soft skills' & $\begin{array}{l}\text { 2.1. Professional competence } \\
\text { 2.2. Communication }\end{array}$ & $\begin{array}{l}\text { "Build some soft skills into the course as well. Communication and } \\
\text { professionalism are two that fall under soft skills." 1FG4 }\end{array}$ \\
\hline \multirow[t]{2}{*}{ 3. Ethics Competence } & $\begin{array}{l}\text { 3.1. Aspects of ethics should be specifically listed } \\
\text { and identified as competencies }\end{array}$ & $\begin{array}{l}\text { "The ethical components... we do have courses. We touch on it } \\
\text { early in the years but it is actually, how can I say, we don't make } \\
\text { enough about it, especially when they go out there. Soft skills, I } \\
\text { think the ethics is also important and we should also be included } \\
\text { with competence and it may be an attribute but it is also a compe- } \\
\text { tency" 1FG6 }\end{array}$ \\
\hline & $\begin{array}{l}\text { 3.2. Ethics to be integral part of the learning } \\
\text { of all competencies and should be specifically } \\
\text { assessed. }\end{array}$ & $\begin{array}{l}\text { "I am not sure if they assess on ethics in the first and second year } \\
\text { I have done it for the last three years so that we have an ethics } \\
\text { lecture in our course so it is supposed to pull first and second year } \\
\text { together but they are not assessed. So every year they must hear } \\
\text { something about ethics and maybe that gets embedded in their } \\
\text { mind, that as an attribute." 1FG4 }\end{array}$ \\
\hline 4. Private Practice Competence & $\begin{array}{ll}1.1 & \text { Business and leadership skills } \\
1.2 & \text { Entrepreneurial skills }\end{array}$ & $\begin{array}{l}\text { "Private practice and the business skill. It is a skill or competency." } \\
2 \text { FG6 } \\
\text { "Entrepreneurial desire and skills to step up on their own." 2FG5 } \\
\text { "Leadership skills, very important." 2FG5 }\end{array}$ \\
\hline
\end{tabular}

ensured. The signed consent forms were collected by the first researcher, at the start of each focus group discussion. The numbers that were assigned to the participants for the focus group discussions, ensured anonymity during the transcription and data analysis. The transcriptions were shared with the participants for member-checking, to ensure the trustworthiness of the data. During this process of generating codes and code groups, one of the research supervisors, cross- checked the codes and code groups, in a further effort to ensure trustworthiness and reliability. An external coder was employed as an additional trustworthy strategy. This external coding was completed, independent of the researcher's coding process. Themes were developed from the coding process, at which stage, the coding of the data from both focus group discussions were considered and reported on simultaneously.

\section{RESULTS}

The responses from both focus group discussions were coded and analyzed together. In the first part of the results, the researchers endeavored to describe the findings of both focus group discussions, regarding the competencies, according to themes, which was followed by a discussion of the interrelated themes, and concluded with an interpretation of the meanings of the themes. In part two of the results, the participants' knowledge of the AfriMEDS core competency framework was outlined, as well as the alignment of the curriculum to it. The participant's responses to the first question: "In your view, what are the competencies that the dental graduates require upon graduation or completion of their dental degree?" were arranged in major competency themes, categories, and relevant quotes from the participants (see Table 1). The findings of each of these major themes, namely, clinical competence, soft skills, ethics competence, and private practice competence, are discussed in the following section.

\section{Major theme 1: Clinical competence}

The introductory comments of the participants revealed that clinical competence was regarded as the priority issue. There was no clear agreement as to what, specifically, this concept entailed; however, overall, it appeared to be regarded as an all-encompassing concept that included knowledge and skills needed/required for diagnosis and treatment. The following quotes outlined the general view of clinical competence:

"Clinical competence is obviously one of the outcomes by the time they reach their final year and then obviously that builds into a lot of other competencies in their different disciplines, that you going to get to whatever specific to the discipline but essentially you want a clinically competent graduate that leaves from here" (1FG1)

"To treat a patient and do no harm and have enough knowledge to perform tasks that are allocated (2FG3) 
Major theme 2: Soft skills: Communication and professionalism

\begin{abstract}
A few participants disclosed that communication was an inherent part of professionalism, and should be assessed as competence. Communication was highlighted as a competency required upon graduation, which is illustrated by the following quotes of the participants:
\end{abstract}

"The ability to communicate with their community and with their patients" (2FG2)

"Learning sign language and learning how to communicate and that is a skill which I think will add competence for that special thing" (1FG6)

Overall, the participants clearly expressed the need for clear descriptors of soft skill competencies, for the ability to assess the level of competencies. The following examples illustrated this sentiment:

"In terms of professionalism, I think a lot more needs to be discussed around that because if you ask one person what professionalism means to him or her, you will find that people define that differently" (2FG1)

"We don't have a uniform understanding of professionalism, then it is very difficult for us to say that this is the competency or the attribute that we want in our student because it would mean so many things"(2FG3)

\section{Major theme 3: Ethics competence}

The participants' discussions indicated that ethical behavior was a required competence; however, clear clarification of the aspects of professional ethical behavior, was not required to be able to assess it. The competence of identifying the basic human value of respect for the individuality and worth/dignity of every patient, was highlighted by some of the participants. Some relevant responses to ethics competence were recorded as follows:

"You need to be professional and they need to be ethical in their behavior and their relationship with their patients and the community" (2FG7)
"Terms of ethics, my understanding of competency that we want to develop in terms of ethics is more of a framework in which they must conduct themselves to be ethical when they do their clinical work and I think that is important"(1FG5)

\section{Major theme 4: Private practice competence}

The communication in the focus groups suggested overwhelming agreement on specific knowledge and skills as competencies to manage private practice. Remarkably, private practice competence was debated, extensively, during both focus group discussions. The specific skills mentioned, when starting a business included, how to construct a business plan, leadership skills, marketing, and financial issues, and managing staff. The following excerpts illustrated this:

"They (students) said 'you guys never prepared us for private practice'. I think then we are falling short because there is a competency that we need to measure or that we have to create or think about." (2FG3)

"Private practice and how to manage a business and how to manage staff" (2FG6)

In addition to the major themes identified and described (see Table 1), the participants highlighted competencies, which they considered important for dental graduates. These competencies, with their relevant quotes, are displayed in Table 2.

\section{Interrelating themes}

For the second layer of analysis, interrelating themes were developed. The HPCSA core competency framework, outlining the key competencies and enabling competencies, ${ }^{10}$ were used as a guide (see Tables 1 and 2). These competencies, as described by the participants, were highlighted in the different interrelating themes or categories.

\section{Health care professional (HCP) / Clinical competence}

The clinical competence, identified by the participants, related to HCP competence. As outlined in the HPCSA's core competency framework" "As health care practitioners,

Table 2: Competencies and quotes identified from focus group

Competency

Collaborator

Digitally competency

Life- long learner

Evidence- based dentistry

Internationalization

\section{Quotes}

"Look at dental research, they work in groups so they collaborate with each other" 2FG4

"To become critical citizens out there and to look to do better to the good of the community." 2FG7

"A competency to see our students to become technologically and digitally competent." 2FG7

'I think it is to make sure our students are life- long learners and that they are able to upskill themselve no matter what they do." 1FG3

"Evidence base, it is a big part of making critical or clinical decisions." 1FG7

"Internationalisation as a competency, making these graduates attributes compatible into not just our society but with the international society." 2FG6

"Trust and respect." 2FG1

"How do you make yourself flexible enough?" 2FG4

"Attributes is like quality, like honest, being thankful, being charitable." 2FG7 
Table 3: Emergent concerns

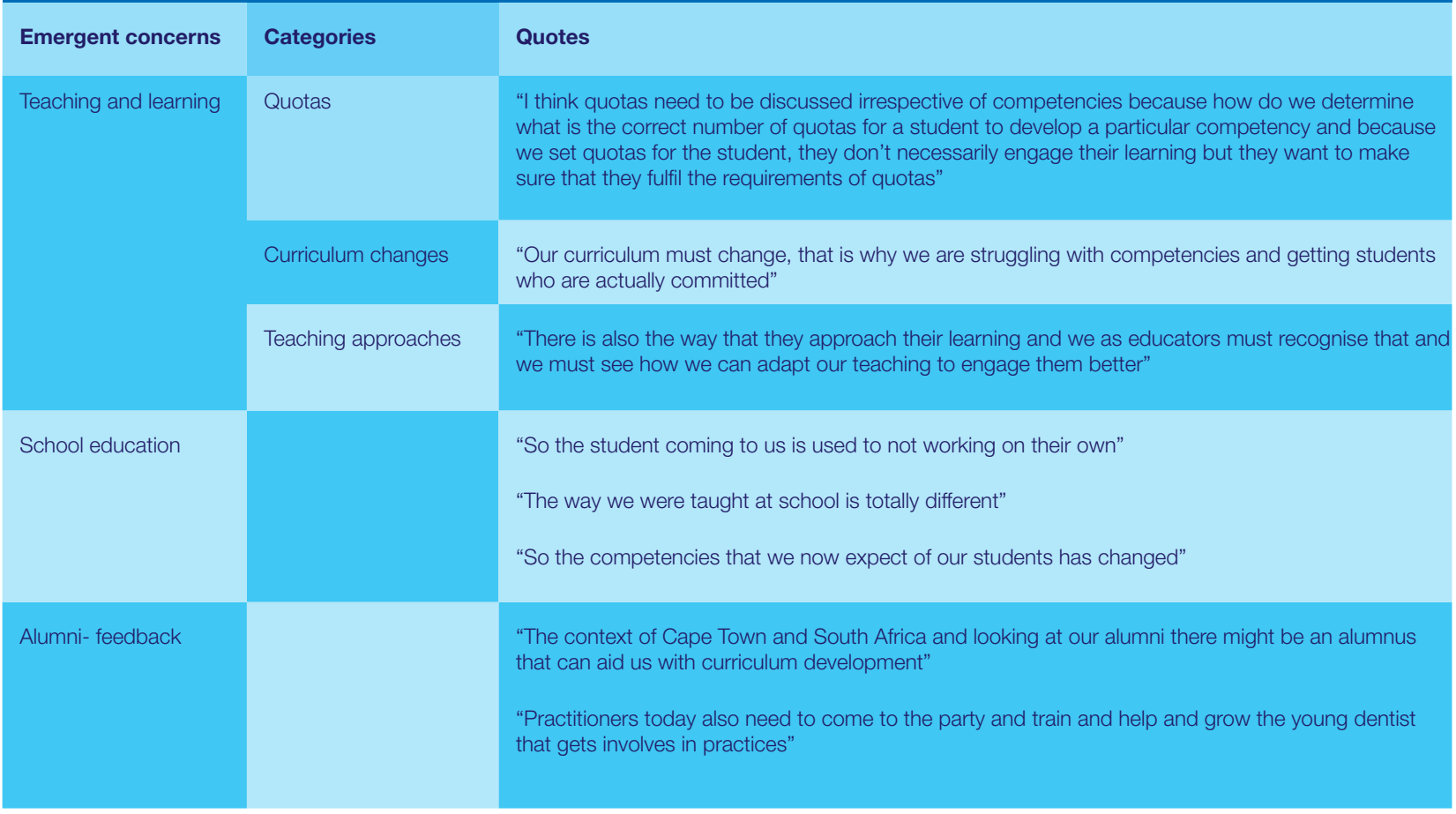

healthcare professionals integrate all of the graduate attribute roles, applying profession-specific knowledge, clinical skills and professional attitudes in their provision of patient/ client- centered care" ( $p$.2). Ethics was also identified as a competency by a few participants. Acquiring the ethical, human rights, and legal principles embedded in healthcare, is one of the enabling competencies included in the role of HCP. Therefore, ethics is interrelated with a HCP and categorized under one theme. The participants shared that dental graduates should base their patient treatment on sound ethical principles. The teaching and the importance of ethics were discussed with the participants in the interviews. According to the findings, the participants expressed that graduates needed to view, as well as treat patients holistically. During the training of students, the ability for students to integrate across the various disciplines of dentistry is challenging, due to the strong discipline- or content-based training. The participants also strongly described record-keeping as a useful HCP competency, while graduate attributes were described as an enabling HCP competency, for example, to provide compassionate, empathetic and patient-centered care, to demonstrate insight into their own limitations of expertise, and to demonstrate a commitment to work in primary healthcare settings.

\section{Communicator}

'As communicators, healthcare professionals effectively facilitate the carer-patient/carer-client relationship and the dynamic exchanges that occur before, during and after interventions' (p.5). ${ }^{10}$ The participants referred to communication and professionalism as soft skills; however, it appeared as a separate core competency in the HPCSA Competency framework (p.5). ${ }^{10}$ 'Establishing positive therapeutic relationships with patients and their families' is described as an enabling competency that could relate to the professionalism, or soft skills, referred to by the participants (p.25). ${ }^{10}$ From the interviews, it was clear that communication was regarded as an important competency for graduates.
Some debate ensued about the teaching and assessment of communication, as well as whether they were appropriate and sufficient at the institution under scrutiny. Teaching of various communication skills, such as role-modelling, were discussed. Verbal and non-verbal communication skills are taught early in the dental undergraduate program; however, concern was raised about the assessment and importance of the integration throughout the senior clinical years. Additionally, communication with colleagues and peers was highlighted as an important skill. The teaching of an appropriate sign language was also suggested, to enable graduates to deal with the hearing-impaired patients.

\section{Collaborator}

'As collaborators, healthcare professionals work effectively within a team to achieve optimal patient/client care' (p.7). ${ }^{10}$ Reference was made to the manner in which students collaborate in groups for courses, such as dental research. There were limited discussions on collaboration, as a competency, as the participants reflected on the teaching of disciplines that occur in silos, referring to their own experiences, as teachers at the institution under scrutiny. Given the emergence and integration of inter-professional health education as a competency in dental education, ${ }^{15}$ it was concerning that collaboration with the dental, or healthcare team was not discussed. This could have been influenced, in part, by the selection of the participants (module coordinators in clinical years) from the dentistry program only.

\section{Scholar}

The participants highlighted critical thinking, evidence-based dentistry, and a life-long learner, as competencies. Collectively, these competencies relate to the role of a scholar of AfriMEDS. As outlined in the HPCSA's core competency framework, 'As scholars, healthcare professionals demonstrate a lifelong commitment to reflective learning as well as the creation, dissemination, application and translation of knowledge' (p.31). ${ }^{10}$ Some of the descriptions of the enabling competencies of the role of a scholar, for example, 
'...critical evaluation of health-related literature', relates well with the participants view (direct quotes) of critical thinking, as competency (p.32). ${ }^{10}$ The participants considered evidence-based dentistry an important competency during the focus group discussions. Although evidence-based is not explicitly referred to in the HPCSA core competency framework, it is implied as an enabling competency, for example, '...critically appraise retrieved evidence for quality and relevance and interpret findings' (p32). ${ }^{10}$ According to Koole et al.,8 evidence-based dentistry is a rather recent phenomenon in dental education. For this current study, it may have influenced some of the participants' translation of evidence-based dentistry, or its full potential as a competency. Consequently, the dentists in this current study may not have fully understood the concept, to value its full potential. Being a life-long learner was identified by the participants as a competency, which the dental graduate required. Lifelong learning is included in the core competency of a scholar as a lifelong commitment to reflective learning, and as an enabling competency, referred to as 'ongoing learning' (p.31). ${ }^{10}$ Reference to upskilling was made, when the lifelong learning competency was discussed during the interviews.

\section{Health advocate}

As outlined in the HPCSA's core competency framework, 'As health advocates, healthcare professionals responsibly use their expertise and influence to advance the health and well-being of individuals, communities and populations' (p.10). ${ }^{10}$ According to the findings, being a health advocate was viewed as a competency, which dental graduates should possess. Concern was raised about students not being exposed to real world circumstances in their communities. The participants perceived that dental students had been struggling to cope and manage their own health problems. Reference was made to substance abuse, as a coping mechanism. Being a health advocate, as a competency, was highlighted as an area of development for the curriculum.

\section{Leader and manager}

Private practice was highlighted as an important competency in the findings. This correlated well with the AfriMEDS's leader and manager role. As outlined in the HPCSA's core competency framework, 'As leaders and managers, healthcare practitioners are integral participants in healthcare organizations, organizing sustainable practices, making decisions about allocating resources, and contributing to the effectiveness of the healthcare system' (p.8). ${ }^{10}$ Private practice was clearly identified as a competency that participants mentioned and discussed, in detail. Certain aspects, mentioned during the interviews, were business and management skills, which relate to the leader and manager core competency. The competencies highlighted by the participants, specifically referred to private practice competencies, such as setting up a private practice, financial planning, and human resource management/planning. Entrepreneurial skills were included in the private practice competency discussion. At the institution under scrutiny, the awareness and development of entrepreneurial skills were identified as areas of development for senior students, in recent years. The majority of the participants expressed their concern that the current curriculum did not prepare the dental graduates, adequately, for private practice. As there are limited public health positions available for graduates after community services, private practice is where most of the graduates will practice. ${ }^{8}$

\section{Professional}

As outlined in the HPCSA's core competency framework, professionals, 'Demonstrate commitment and accountability to their patients/clients, other healthcare professions and society through ethical practice' (p.13). ${ }^{10}$ According to the findings, professionalism was emphasized as a competency for all dental graduates. Some participants categorized it as a soft skill, and included professionalism and communication. It was evident that there was no common understanding of professionalism, including professionalism for students and staff.

\section{Digital competence and internationalization}

The importance of being digitally and technologically competent, was viewed as critical by the participants. They agreed that this should be included as a competence. As digital dentistry is one of the developmental areas, training becomes essential. Similarly, the participants viewed internationalization as an emergent competence. It was emphasized that dental graduates should be able to relate to our society, as well as the international society.

\section{Emerging concerns}

Besides highlighting the competencies for dental graduates, the participants were more concerned about the process of achieving the stated competencies. The following issues emerged: teaching and learning issues; high school education; and the value or influence of alumni from the dental faculty on the dental curriculum; which were debated, extensively, in both focus group discussions. Table 3 outlines the major views, as well as these emerging concerns.

Concerns and discussion about the strategies employed to teach students were shared. Suggestions about adapting strategies were centered on the millennials (also known as Generation Y, anyone born between 1981-1996), with the acknowledgement that they learnt differently, which emphasized the importance on adapting teaching and assessment approaches. It was clear that the focus group discussions provided a safe space for teachers to share their thoughts and offer suggestions. It was suggested that the faculty should create regular forums for teachers to share their experiences. Quotas, as indicated in Table 3 refers to number of clinical procedures required for clinical disciplines. This issue emerged prominently, and elicited an in-depth discussion. Disciplines vary regarding their clinical assessments, as well as the application of quantitative clinical requirements (quotas). For some disciplines, the quotas form a large proportion of the clinical progress of students. The participants were able to articulate the competencies required for the dental graduate; however, they were more concerned about how these competencies were being taught and assessed.

The participants were concerned about the school education's influence on the university student. Concerns were raised about the change of school curriculum, and its subsequent effects on teaching and learning at university level. The opinions raised related to the per- 
ception of non-alignment between school and university. The participants concurred about the value of alumni feedback on the curriculum. The alumni of the dental school could provide essential information, regarding the strengths and weaknesses of the curriculum, which they had experienced. ${ }^{7}$ However, the views, or input from the alumni of this particular dental school was not explored in the curriculum review, in the past, as well as the present. In addition, the participants explored the ways in which alumni could assist with assisting and preparing dental graduates for practice, specifically private practice. This could assist the university to prepare dental graduates for private practice, in the form of a mentorship-model.

Alignment to AfriMEDS core competency framework When asked about the term, AfriMEDS, the participants were not familiar with the name; however, for some, CanMEDS was a familiar framework. However, the participants related well, and were familiar with the HPCSA-core competency framework. Details of the manner in which competencies relate to the undergraduate dental curriculum, were unclear to the participants; however, they were able to describe most competencies required by the HPCSA.

Interestingly, the responses to whether this dental curriculum was aligned with the AfriMEDS competency framework varied. Some were of the opinion that there was alignment, and that the undergraduate dental curriculum included most of the AfriMEDS competencies. Collaborator was highlighted, by some participants, as competency that was not aligned, suggesting that this be addressed in the current curriculum. Teaching, learning, and assessment of the competencies, professionalism, and communication, were viewed as necessary improvements in the faculty.

The participants indicated that, although some of the competencies were not included in the formal curriculum documents (e.g. Dentistry calendar), it was taught within the modules. As an example, one of the participants disclosed how communication was taught as part of one module in the clinical setting and classroom, although this competency was not included in the formal curriculum (dental calendar). In addition, one participant's view was that "we have a delusion on what we have", implying the appearance of a lack of transparency and coherency in the curriculum. As part of an institution, the required curriculum framework programs need to be aligned, creating some tension with the discipline-specific requirements, for example, the HPCSA requirements. Specific Graduate Attributes is regarded as one of the pillars of the institution's curriculum framework. The HPCSA core competency framework includes graduate attributes in the HCP competency, thus enabling the dental curriculum to interlace both requirements.

\section{DISCUSSION}

In this current study, the researchers aimed to explore and describe dental educators' views of the competencies required in the AfriMEDS core competency framework, and its alignment with the undergraduate curriculum. The results of the focus group discussions indicated that dental educators required some guidance and clarity regarding the AfriMEDS core competency framework. However, they were able to identify the competencies related to the AfriMED core competency framework, through their experiences and views. It became apparent that the current coursework taught in the various disciplines, were not always reflected in the formal curriculum. The discussions highlighted how most dental educators were strongly rooted in their specific disciplines, with a limited holistic view of the entire undergraduate dental curriculum, as well as the factors that guide the program. Dental educators' roles included: teaching and assessments in classrooms, as well as clinical settings; related administration; research; and dedicated departmental roles. Evidently, the dental educators were more concerned about the teaching and assessment of competencies, than the actual competencies. The results of a recent study highlighted that dental education endorsed learning domains as essential for the training of competent dentists; however, educators may experience difficulty with defining and assessing student outcomes in these areas. ${ }^{16}$ It could be argued that this probably stems from the dental educators' level of involvement in the accreditation and curriculum development processes. Depending on the organizational structure, which is the mechanism that coordinates and manages the academic agenda of the school, the dental educators' level of engagement of may vary.

Therefore, in this current study it appeared that dental educators' views were influenced by their exposure to, and experience of seeing the bigger picture of the complete curriculum. Kadagad et al. ${ }^{17}$ suggests a focus group discussion, with graduates, students, faculty, and alumni, regarding their perceptions of the curriculum's strengths and weaknesses, as one way to understand and evaluate an existing curriculum. If they are solely focused on their specific discipline, it may limit their appreciation of viewing the dental graduate as ready, for independent practice in the 21 st century. ${ }^{15}$

The competencies that were identified as required by dental graduates, were aligned with the AfriMEDS core competencies. Two of these competencies, namely, evidence-based dentistry, and private practice, were highlighted as core competencies in this current study; however, in AfriMEDS, only aspects of these are described. Similarly, the findings of a study conducted by Koole et al. ${ }^{8}$ revealed that certain professional competences, namely, dental practice management, accountancy, and taxation or stress-management, may be under-exposed.

Digital competency and internationalization were additional competencies highlighted as required by dental graduates. Practicing dentistry in the 21st century, is strongly supported by digital dentistry, and rapid developing technology that would support the inclusion of digital competency into the dental curricula. Koole et al. ${ }^{8}$ confirmed that, to maintain a high quality of dental care, a strategy should be developed, through which dental curricula would be benchmarked, continuously, against an evolving clinical reality.

\section{CONCLUSION}

The findings from this study were able to explore and describe the dental educators' views of the competencies required within the AfriMEDS core competency 
framework. In addition, the views of the dental educators' views regarding the alignment of the AfriMEDS core competencies with the institution's undergraduate curriculum varied. Dental educators were able to reflect on the dental curriculum, as well as make valuable recommendations about the inclusion, integration, teaching, and assessment of core competencies. These recommendations for the undergraduate dental curriculum, at this selected institution, included that the role of collaborator needed to be reviewed throughout the curriculum, while the teaching, learning, and assessment of the communication and professional competency, also needed to be reviewed. Future curriculum review processes, therefore, would need to be informed by the requirements of the HPCSA, as well as the institution's specific requirements, to achieve a coherent and integrated curriculum.

In this current study, the researchers highlighted the importance of engaging all stakeholders, especially dental educators, in curriculum planning and accreditation processes. When curriculum changes are proposed, involvement is the key to success, and efforts should be aimed at including as many stakeholders as possible, at different levels. ${ }^{17}$ This would facilitate more inclusive and consultative processes, as suggested in this current study that dental educators could provide valuable recommendations for additional competencies requirements.

\section{Disclosure}

The authors declare no conflict of interest.

\section{References}

1. Formicola AJ, Bailit H, Beazoglou T, Tedesco L. Advancing dental education in the 21st century: phase 2 report on strategic analysis and recommendations. J Dent Educ. 2018: 82(10) eS1-eS32.

2. Yip H-K, Smales RJ. Review of competency-based education in dentistry. Br Dent J. 2000: 189(6) 324-326.

3. Altman D, Mascarenhas AK. New competencies for the 21st century dental public health specialist. J Public Health Dent. 2016: 76 S18-28.

4. Cowpe J, Plasschaert A, Harzer W, Vinkka- Puhakka H, Walmsley AD. Profile and competences for the graduating European dentist-update 2009. Eur J Dent Educ 2010: 14(4) 193-202. https://doi.org/10.1111/j.1600-0579.2009.00609.x

5. Ditmyer M, Mobley C, Davenport W. Evaluation of an integrative model for professional development and research. J Dent Educ. 2013: 78(3) 368-379.

6. Gerrow J, Murphy J, Boyd M. Review and revision of the competencies for a beginning dental practitioner in Canada. J Can Dent Assoc. 2007: 73(2) 157-160.

7. Ghafoor S, Khan JS. Outcome-based dental education and identification of practice gaps; a narrative review. J Pak Dent Assoc. 2019: 2 41-46.

8. Koole S, Van Den Brulle S, Christiaens V, Jacquet W, Cosyn J, De Bruyn, $\mathrm{H}$. Competence profiles in undergraduate dental education: a comparison between theory and reality. BMC Oral Health 2017: 17(1) 41-46. https://doi.org/10.25301/JPDA.281.41

9. Van Heerden B. Effectively addressing the health needs of South Africa's population: The role of health professions education in the 21st century. S Afr Med J. 2013: 103(1) 21-22. https://doi. org/10.7196/SAMJ.6463.

10. Health Professions Council of South Africa [HPCSA]. Core competencies or undergraduate students in clinical associate, dentistry and medical teaching and learning programmes in South Africa. Unpublished 2014. At: http://www.hpcsa.co.za/ uploads/editor/UserFiles/downloads/medical_dental/MDB\%20 Core\%20Competencies\%20-\%20ENGLISH\%20-\%2OFINAL\% 202014.pdf. September 17, 2018.

11. Benzian H, Greenspan JS, Barrow J et al. A competency matrix for global oral health. J Dent Educ. 2015: 79(4) 353-361.

12. Perez A, Green JL, Starchuk $C$ et al. Dental faculty and student views of didactic and clinical assessment. A qualitative description study. Eur J Dent. Educ 2020: May 13. https://doi. org/10.1111/eje.12541

13. Creswell J. Research design: Qualitative, quantitative and mixed methods approaches. 3rd ed. Thousand Oaks, CA., USA: Sage, 2009.

14. Gavin H. Designing qualitative research: Understanding research methods and statistics in psychology. London, England, United Kingdom: Sage Publications Ltd, 2013. https://dx/doi. org/10.4135/9781446214565. 244-250.

15. Weintraub JA, Quinonez RB, Friga PN, Kowlowitz V, Ciarrocca K. Development of a Dental school strategic plan to inform interprofessional education. J Dent Educ. 2019: 83(12) 1411-1419.

16. Hoskin ER, Johnsen DC, Saksena Y et al. Dental Educators' Perceptions of Educational Learning Domains. J Dent Educ. 2019: 83(1) 79-87.

17. Kadagad P, Tekian A, Pinto PX, Jirge VL. Restructuring an undergraduate dental curriculum to global standards - a case study in an Indian dental school. Eur J Dent Educ. 2012: 16(2) 97-101. 